\title{
Teachers’ Knowledge and Misconceptions of Attention Deficit/Hyperactivity Disorder
}

\author{
Keetam D. F. Alkahtani \\ Department of Special Education, College of Education, King Saud University, Riyadh, KSA \\ Email: kalkahtani@ksu.edu.sa
}

Received August 21 $1^{\text {st }}, 2013$; revised September 24 ${ }^{\text {th }}, 2013$; accepted October $17^{\text {th }}, 2013$

\begin{abstract}
Copyright (c) 2013 Keetam D. F. Alkahtani. This is an open access article distributed under the Creative Commons Attribution License, which permits unrestricted use, distribution, and reproduction in any medium, provided the original work is properly cited. In accordance of the Creative Commons Attribution License all Copyrights (C) 2013 are reserved for SCIRP and the owner of the intellectual property Keetam D. F. Alkahtani. All Copyright (C) 2013 are guarded by law and by SCIRP as a guardian.
\end{abstract}

Teachers can play a key role in identifying and supporting students with Attention Deficit/Hyperactivity Disorder (ADHD). In order to fulfill this important role, it is imperative for teachers to have explicit knowledge about ADHD. The overall aim of this study is to investigate teachers' knowledge and misconceptions of ADHD. Four hundred and twenty-nine (429) teachers participated. The Knowledge of Attention Deficit Disorder Scale (KADDS) along with a demographic questionnaire was used as the survey instruments to collect data. Descriptive statistics and correlation test were used to analyze the data. Results indicated that teachers' knowledge of ADHD was insufficient. Teachers' level of knowledge of ADHD was positively related to their prior training and experience with ADHD (i.e., the number of ADHD courses taken in college or graduate level, and the number of workshops pertaining to ADHD). Teachers' level of knowledge of ADHD also correlated positively with their level of confidence in teaching a student with ADHD. In spite of a few limitations, the results of this study are valuable for identifying areas where there is a misperception or lack of knowledge among teachers.

Keywords: Attention Deficit/Hyperactivity Disorder (ADHD); Teachers’ Knowledge; Misconceptions of ADHD

\section{Introduction}

Attention Deficit/Hyperactivity Disorder (ADHD), defined by the American Psychiatric Association as a disorder is characterized by a persistent pattern of inattention and/or hyperactivity-impulsivity that is more frequently displayed and more severe than is typically seen in individuals at a comparable level of development (APA, 2000). ADHD is one of the most commonly diagnosed psychiatric disorders of childhood. The American Psychiatric Association, in 2000, estimated the prevalence rate of ADHD to be 3\% - 7\% among school-age children (APA, 2000). Additionally, in 2004, the American Academy of Pediatrics reported that $6 \%$ - 9\% of school students have ADHD (AAP, 2004). Given the rate of children with ADHD, most researchers estimated that in every mainstream classroom there will be at least one child with ADHD (Barkley, 2006; DuPaul \& Stoner, 2003; DuPaul \& Weyandt, 2006; Goldstein et al., 2011). Children with ADHD have significant problems with attention, hyperactivity, and impulsivity which usually cause serious impairments in many areas of functioning (e.g., interpersonal and social relationships, and academic performance). Children with ADHD are often non-compliant with commands, disruptive in the classroom, and impulsive in their behaviors. These children tend to be lagging behind academically and can require extra time and energy from their teachers. Because of these problematic behaviors, teaching children with ADHD can be a hard task for most teachers (Selikowitz, 2004).
Having knowledge of ADHD can increase teachers' confidence in teaching and managing children with ADHD (Curtis et al., 2006; DuPaul \& Stoner, 2003).

ADHD has intrigued researchers and become the most researched of all the developmental behavioral disorders. Conversely, ADHD continues to generate controversy. Cooper and Ideus (2002) asserted that "unfortunately, to date, some of the popular debate about [ADHD] has generated far more heat than light” (p. vii). Over the past decade, most published research studies in the area of ADHD have focused on etiology, assessment, and treatment of this disorder. There are also researches concerned with children with ADHD in educational settings. However, only a small number of studies have been conducted to examine teachers' knowledge and misperception of ADHD. These researches were undertaken following the release of the guidelines for diagnosing children with ADHD (Jerome et al., 1994; Pelham \& Evans, 1992). The Diagnostic and Statistical Manual of Mental Disorders, Fourth Edition, Text Revised (DSM-IV-TR) states that symptoms of ADHD must be presented in two or more settings, such as home and school (APA, 2000). Teachers are valuable sources of information with regard to diagnosis of ADHD because of their daily contact with children in a variety of settings (Bussing et al., 1998; Pelham \& Evans, 1992). Teachers are frequently involved in the assessment process. According to Carey (1999) more than half of the primary care pediatricians used school reports to arrive at their 
diagnosis of child with ADHD. The goal of diagnosis should not be the diagnosis itself, rather plan interventions that based on the information gathered in the assessment phase (Du-Paul \& Stoner, 2003).

Therefore, teachers should have accurate knowledge with which they can effectively participate in the process of the assessment and treatment decision-making for children with ADHD. Unfortunately, few studies that have attempted to assess teachers' knowledge of ADHD suggest that teachers often lack knowledge of ADHD and they tend to have substantial misperceptions about the nature, course, causes and outcomes of ADHD (Barbaresi \& Olsen, 1998; Jerome et al., 1994; Sciutto et al., 2000; Snider et al., 2003; Vereb \& DiPerna, 2004; West et al., 2005; Weyandt et al., 2009). It was also found that teachers have received little, if any, training related to ADHD (Bussing et al., 2002; Jerome et al., 1994; Sciutto et al., 2000; Kos et al., 2004). This is alarmingly considered that teachers are primarily responsible for referring children with ADHD for assessment, and their frequent involvement in the treatment process (Barkley, 2006; Bussing et al., 2002). This research attempts to further previous studies that investigated teachers' knowledge of ADHD. Specifically, this research investigated three questions. The questions are:

- What is the teachers' level of knowledge of ADHD?

- Is there relationship between teachers' level of knowledge of ADHD and their prior training and experience with ADHD (the number of ADHD courses taken in college or graduate level, and the number of workshops pertaining to ADHD)?

- Is there relationship between teachers' level of knowledge of ADHD and their level of confidence in teaching a student with ADHD?

\section{Method}

This is a descriptive research using self-reported questionnaire method. Survey research provide a broad overview of information collected from representative sample of a large population so that inferences can be made about their knowledge, attitudes, characteristics, or behaviors (Cresswell, 2008). This type of research is quantitative in nature and often grounded upon existing practice which allows "making careful descriptions of educational phenomena" (Gall et al., 2007: p. 300 ). Previous researchers considered survey design as an efficient method in collecting original data to measure teachers' knowledge about ADHD (Bekle, 2004; Brooka et al., 2000; Canu \& Mancil, 2012; Ghanizadeh, et al., 2006; Kos et al., 2004; Jerome et al., 1994; Ohan et al., 2008; Sciutto et al., 2000; Snider et al., 2003; Vereb \& DiPerna, 2004; West et al., 2005; White et al., 2011). Self-reported questionnaire method has been chosen, as it is the best available method to achieve the aim of this research.

\section{Procedure}

The The Knowledge of Attention Deficit Disorders Scale (KADDS) was obtained from Professor Mark Sciutto, who granted permission for the use of KADDS in this research. Permission to conduct this research was obtained from the research department at the middle region. The participants were recruited from thirty-seven (37) randomly selected schools in the middle region. A total of two thousand (2000) questionnaires were administered to preschool through ninth grade school teachers. A letter was attached to each questionnaire. The letter explains the purpose of the study and thanking teachers for their cooperation. It was emphasized in the letter that taking part in this study is voluntary, and teachers are not required to identify themselves or their schools on the questionnaire. No incentive was provided for participation. Of the two thousand (2000) questionnaires distributed, four hundred and thirty-one (431) were returned. Two questionnaires were not usable due to substantial missing data. The total number of usable questionnaires for data analysis was four hundred and twenty-nine (429); a usable response rate of more than twenty one percent (21.45\%).

\section{Data Collection}

The Knowledge of Attention Deficit Disorders Scale (KADDS) and a demographic questionnaire were used to collect data from four hundred and twenty-nine (429) teachers. The KADDS is a 36-item rating scale developed by Sciutto and colleagues (Sciutto et al., 2000) to measure teachers' knowledge and misperceptions of Attention-Deficit/Hyperactivity Disorder. Items in the KADDS questionnaire phrased as statements about ADHD with three option response format: true (T), false (F) or don't know (DK). These items divided into three specific areas: symptoms/diagnosis of ADHD (9 items), the treatment of ADHD (12 items), and general knowledge about the nature, causes and outcome of ADHD (15 items). The KADDS format allows for the differentiation between what teachers do not know from their misperception of ADHD (Sciutto et al., 2000; Soroa et al., 2013). The KADDS is considered to be "one of the most widely used instruments to assess the level of knowledge of teachers regarding ADHD, and is the first instrument whose indices of reliability and validity were published in this field” (Soroa et al., 2013: p. 156). Internal consistency of the KADDS total score, in previous studies, has ranged from 0.82 to 0.89 (Herbert et al., 2004; Sciutto et al., 2000; Soroa et al., 2013). Cronbach's alpha value for the current study was 0.76 which indicate an adequate internal consistency.

\section{Results and Discussion}

Data gathered from the demographic questionnaire and KADDS were analyzed using a computer statistical software program, Statistical Package for the Social Sciences (SPSS). Descriptive statistics were used to describe characteristics of the study participants. The mean age of the participants was 34.18 (range, 23 - 59 years), with a standard deviation of 7.61. Participants reported an average of 10.48 years of teaching experience (standard deviation $=7.45$; range, 1 - 39 years). As shown on Table 1, forty four and a half percent $(44.5 \%, \mathrm{n}=$ 191) of the participants were male, and fifty five and a half percent $(55.5 \%, \mathrm{n}=238)$ were female. In terms of participants' education, the vast majority had a bachelor's degree $(96.5 \%, \mathrm{n}$ $=414)$; while less than four percent $(3.3 \%, \mathrm{n}=14)$ were holding a master degree. Of the 429 participants, 389 (90.7\%) were general education teachers, and 40 (9.3\%) were special education teachers. The number of respondents from urban areas was 379 (88.3), while 35 (8.2\%) from suburban, and 15 (3.5\%) from schools located in rural areas.

Teachers' overall percentage score of correct responses (items answered correctly) was $17.2 \%$ which reflect poor knowledge of ADHD. Incorrect responses (items answered incorrectly) percentage was $23 \%$ which indicate misperceptions 
Table 1.

The demographic characteristics of the participants $(N=429)$.

\begin{tabular}{ccc}
\hline Variable & Frequency $(n)$ & Percentage (\%) \\
\hline Gender & & \\
Male & 191 & 44.5 \\
Female & 238 & 55.5 \\
Educational Level & & \\
Bachelor degree. & 414 & 96.5 \\
Master degree. & 14 & 3.3 \\
Doctoral degree. & 0 & 0 \\
Educational Role & & \\
General education teacher. & 389 & 90.7 \\
Special education teacher. & 40 & 9.3 \\
School Location & & \\
Rural. & 15 & 3.5 \\
Suburban. & 35 & 8.2 \\
Urban. & 379 & 88.3 \\
\hline
\end{tabular}

of ADHD. Don't know responses (items that teachers admitted they just don't know) percentage was $59.8 \%$ which point to a lack of knowledge of ADHD among teachers. Teachers' overall percentage score of the correct, incorrect, and don't know responses are presented graphically in Figure 1.

In order to examine teachers' knowledge within each of the KADDS subscales, their responses were grouped to represent the three subscales of KADDS. Table 2 presents teachers' responses on the first subscale which include 15 items assessing general knowledge about the nature, causes and outcome of ADHD. Nearly seventeen (16.8\%) of the teachers responded correctly, while (26.2\%) responded incorrectly, and (57\%) responded "don't know" to these items. The highest proportion of correct responses $(30 \%, \mathrm{n}=129)$ and also the lowest incorrect responses $(4 \%, n=17)$ were on item 32 , "The majority of ADHD children evidence some degree of poor school performance in the elementary school years", which signify that only less than the third of the teachers knew that most children with ADHD have difficulty with academic performance. The lowest proportion of correct responses $(3.5 \%, \mathrm{n}=15)$ and also the highest incorrect responses $(68.1 \%, \mathrm{n}=292)$ were on item 22, "If an ADHD child is able to demonstrate sustained attention to video games or TV for over an hour, that child is also able to sustain attention for at least an hour of class or homework", which indicate that the majority of teachers have misconceptions about the change of ADHD symptoms across tasks and settings. The majority of teachers $(76.7 \%, \mathrm{n}=329)$ selected "don't know" option to answer item 28, "There are specific physical features which can be identified by medical doctors (e.g. pediatrician) in making a definitive diagnosis of ADHD”, which point out that more than two-third of the teachers showed lack of knowledge about the fact that there is no medical examination to confirm the diagnosis of ADHD.

Table 3 presents teachers' responses on the second subscale of KADDS which include 9 items assessing symptoms/diagnosis of ADHD. Eighteen and one-tenth percent (18.1\%) of the teachers responded correctly, while $(22.8 \%)$ responded incorrectly, and (59.1\%) responded “don't know" to these items. The highest proportion of correct responses $(38.9 \%, \mathrm{n}=167)$ was on item 9, "ADHD children often fidget or squirm in their seats”, which indicate that less than half of the teachers were

\section{Overall knowledge of ADHD}

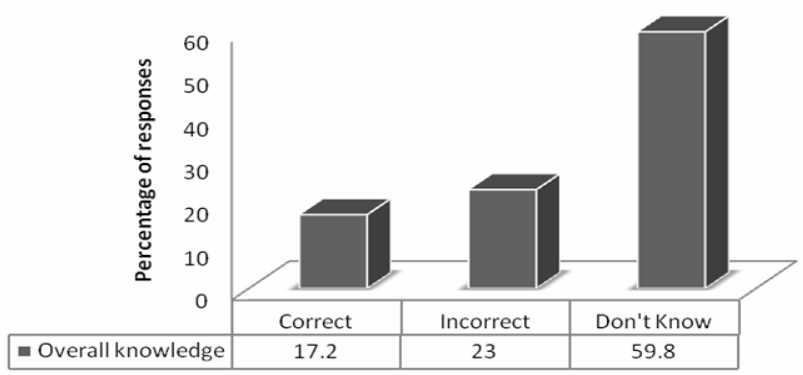

Figure 1.

Teachers' overall percentage score of the correct, incorrect, and don't know responses on the KADDS.

aware of one of the hallmark symptoms of ADHD. The lowest proportion of correct responses $(13.3 \%, \mathrm{n}=57)$ and also the highest incorrect responses $(19.6 \%, \mathrm{n}=84)$ were on item 11 , "It is common for ADHD children to have an inflated sense of self-esteem or grandiosity", which show that less than onefourth of the teachers thought mistakenly that children with ADHD have an inflated self-esteem. The majority of teachers (77.9\%, $\mathrm{n}=334$ ) selected “don't know” option to answer item 16, "Current wisdom about ADHD suggests two clusters of symptoms: One of inattention and another consisting of hyperactivity/impulsivity", which point out that more than two-third of the teachers showed lack of knowledge about the subtypes of ADHD.

Table 4 presents teachers' responses on the third subscale of KADDS which include 12 items assessing the treatment of ADHD. Sixteen and six-tenth percent (16.6\%) of the teachers responded correctly, while $(20.4 \%)$ responded incorrectly, and (63\%) responded “don't know" to these items. The highest proportion of correct responses $(26.3 \%, n=113)$ was on item 10, "Parent and teacher training in managing an ADHD child are generally effective when combined with medication treatment", which indicate that only about the fourth of the teachers knew that an effective treatment of ADHD should be multifaceted and comprehensive. The highest proportion of incorrect responses $(26.8 \%, \mathrm{n}=115)$ was on item 23 , "Reducing dietary intake of sugar or food additives is generally effective in reducing the symptoms of ADHD”, which show that more than one-fourth of the teachers hold a misperception about the effectiveness of the diet on the symptoms of ADHD as they thought mistakenly that the symptoms of ADHD will reduce with the reduction of sugar and or food additives in the diet of children with ADHD. The lowest proportion of both correct responses $(7 \%, \mathrm{n}=30)$ and incorrect responses $(4.4 \%, \mathrm{n}=19)$ were on item 35, "Electroconvulsive Therapy (i.e. shock treatment) has been found to be an effective treatment for severe cases of ADHD”. Responses on this item revealed that although less than five percent of the teachers have a misperception, only seven percent were aware that there is no evidence of the effectiveness of this type of treatment for children with ADHD. Item 35 also has the highest percentage $(88.3 \%, n=379)$ for don't know responses, pointing to lack of knowledge among the majority of the teachers.

Percentage of teachers' score of the correct, incorrect, and don't know responses on the KADDS subscales are presented graphically in Figure 2.

Two-tailed Pearson correlation analysis was computed to in- 


\section{K. D. F. ALKAHTANI}

Table 2.

Participants' responses on the first subscale of KADDS which include 15 items pertain to general knowledge about the nature, causes and outcome of $\operatorname{ADHD}(N=429)$.

\begin{tabular}{|c|c|c|c|c|}
\hline \multirow{2}{*}{ Items } & \multirow{2}{*}{ CA } & \multicolumn{3}{|c|}{ Number of responses } \\
\hline & & Correct & Incorrect & Don't Know \\
\hline 1. Most estimates suggest that ADHD occurs in approximately $15 \%$ of school age children. & F & $\begin{array}{c}62 \\
(14.5 \%)\end{array}$ & $\begin{array}{c}50 \\
(11.7 \%)\end{array}$ & $\begin{array}{c}318 \\
(73.7 \%)\end{array}$ \\
\hline 4. ADHD children are typically more compliant with their fathers than with their mothers. & $\mathrm{T}$ & $\begin{array}{c}69 \\
(16.1 \%)\end{array}$ & $\begin{array}{c}53 \\
(12.4 \%)\end{array}$ & $\begin{array}{c}303 \\
(70.6)\end{array}$ \\
\hline $\begin{array}{l}\text { 6. ADHD is more common in the } 1 \text { st degree biological relatives (i.e. mother, father) of children with } \\
\text { ADHD than in the general population. }\end{array}$ & $\mathrm{T}$ & $\begin{array}{c}81 \\
(18.9 \%)\end{array}$ & $\begin{array}{c}49 \\
(11.4 \%)\end{array}$ & $\begin{array}{c}296 \\
(69.7 \%)\end{array}$ \\
\hline 13. It is possible for an adult to be diagnosed with ADHD. & $\mathrm{T}$ & $\begin{array}{c}57 \\
(13.3 \%)\end{array}$ & $\begin{array}{c}60 \\
(14.1 \%)\end{array}$ & $\begin{array}{c}309 \\
(72.1 \%)\end{array}$ \\
\hline 17. Symptoms of depression are found more frequently in ADHD children than in non-ADHD children. & $\mathrm{T}$ & $\begin{array}{c}47 \\
(11 \%)\end{array}$ & $\begin{array}{c}62 \\
(14.5 \%)\end{array}$ & $\begin{array}{c}318 \\
(74.5 \%)\end{array}$ \\
\hline $\begin{array}{l}\text { 19. Most ADHD children "outgrow" their symptoms by the onset of puberty and subsequently function } \\
\text { normally in adulthood. }\end{array}$ & $\mathrm{F}$ & $\begin{array}{c}29 \\
(6.8 \%)\end{array}$ & $\begin{array}{c}78 \\
(18.2 \%)\end{array}$ & $\begin{array}{c}320 \\
(74.6 \%)\end{array}$ \\
\hline $\begin{array}{l}\text { 22. If an ADHD child is able to demonstrate sustained attention to video games or TV for over an hour, } \\
\text { that child is also able to sustain attention for at least an hour of class or homework. }\end{array}$ & $\mathrm{F}$ & $\begin{array}{c}15 \\
(3.5 \%)\end{array}$ & $\begin{array}{c}292 \\
(68.1 \%)\end{array}$ & $\begin{array}{c}121 \\
(28.2 \%)\end{array}$ \\
\hline 24. A diagnosis of ADHD by itself makes a child eligible for placement in special education. & $\mathrm{F}$ & $\begin{array}{c}30 \\
(7.0 \%)\end{array}$ & $\begin{array}{c}104 \\
(24.2 \%)\end{array}$ & $\begin{array}{c}292 \\
(68.1 \%)\end{array}$ \\
\hline 27. ADHD children generally experience more problems in novel situations than in familiar situations. & F & $\begin{array}{c}50 \\
(11.7 \%)\end{array}$ & $\begin{array}{c}54 \\
(12.6 \%)\end{array}$ & $\begin{array}{c}323 \\
(75.3 \%)\end{array}$ \\
\hline $\begin{array}{l}\text { 28. There are specific physical features which can be identified by medical doctors (e.g. pediatrician) in } \\
\text { making a definitive diagnosis of ADHD. }\end{array}$ & $\mathrm{F}$ & $\begin{array}{c}23 \\
(5.4 \%)\end{array}$ & $\begin{array}{c}73 \\
(17 \%)\end{array}$ & $\begin{array}{c}329 \\
(76.7 \%)\end{array}$ \\
\hline 29. In school age children, the prevalence of ADHD in males and females is equivalent. & $\mathrm{F}$ & $\begin{array}{c}28 \\
(6.5 \%)\end{array}$ & $\begin{array}{c}78 \\
(18.2 \%)\end{array}$ & $\begin{array}{c}320 \\
(74.6 \%)\end{array}$ \\
\hline $\begin{array}{l}\text { 30. In very young children (less than } 4 \text { years old), the problem behaviors of ADHD children (e.g. } \\
\text { hyperactivity, inattention) are distinctly different from age-appropriate behaviors of non-ADHD children. }\end{array}$ & $\mathrm{F}$ & $\begin{array}{c}38 \\
(8.9 \%)\end{array}$ & $\begin{array}{c}79 \\
(18.4 \%)\end{array}$ & $\begin{array}{l}309 \\
(72 \%)\end{array}$ \\
\hline $\begin{array}{l}\text { 31. Children with ADHD are more distinguishable from normal children in a classroom setting than in a } \\
\text { free play situation. }\end{array}$ & $\mathrm{T}$ & $\begin{array}{c}64 \\
(14.9 \%)\end{array}$ & $\begin{array}{c}42 \\
(9.8 \%)\end{array}$ & $\begin{array}{c}322 \\
(75.1 \%)\end{array}$ \\
\hline $\begin{array}{l}\text { 32. The majority of ADHD children evidence some degree of poor school performance in the elementary } \\
\text { school years. }\end{array}$ & $\mathrm{T}$ & $\begin{array}{c}129 \\
(30 \%)\end{array}$ & $\begin{array}{c}17 \\
(4 \%)\end{array}$ & $\begin{array}{c}283 \\
(66 \%)\end{array}$ \\
\hline $\begin{array}{l}\text { 33. Symptoms of ADHD are often seen in non-ADHD children who come from inadequate and chaotic } \\
\text { home environments. }\end{array}$ & $\mathrm{T}$ & $\begin{array}{c}68 \\
(15.9 \%)\end{array}$ & $\begin{array}{c}40 \\
(9.3 \%)\end{array}$ & $\begin{array}{c}320 \\
(74.6 \%)\end{array}$ \\
\hline
\end{tabular}

$\mathrm{CA}=$ Correct Answer; $\mathrm{T}=$ True; $\mathrm{F}=$ False

Table 3.

Participants' responses on the second subscale of KADDS which include 9 items pertain to symptoms/diagnosis of ADHD $(N=429)$.

\begin{tabular}{|c|c|c|c|c|}
\hline \multirow{2}{*}{ Items } & \multirow{2}{*}{ CA } & \multicolumn{3}{|c|}{ Number of responses } \\
\hline & & Correct & Incorrect & Don’t Know \\
\hline 3. ADHD children are frequently distracted by extraneous stimuli. & $\mathrm{T}$ & $\begin{array}{c}109 \\
(25.4 \%)\end{array}$ & $\begin{array}{c}47 \\
(11.2 \%)\end{array}$ & $272(63.4 \%)$ \\
\hline $\begin{array}{l}\text { 5. In order to be diagnosed with ADHD, the child's symptoms must have been } \\
\text { present before age } 7 \text {. }\end{array}$ & $\mathrm{T}$ & $\begin{array}{c}68 \\
(15.9 \%)\end{array}$ & $\begin{array}{c}49 \\
(11.4 \%)\end{array}$ & $\begin{array}{c}296 \\
(71.3 \%)\end{array}$ \\
\hline 7. One symptom of ADHD children is that they have been physically cruel to other people. & $\mathrm{F}$ & $\begin{array}{c}59 \\
(13.8 \%)\end{array}$ & $\begin{array}{c}75 \\
(17.5 \%)\end{array}$ & $\begin{array}{c}291 \\
(68.5 \%)\end{array}$ \\
\hline 9. ADHD children often fidget or squirm in their seats. & $\mathrm{T}$ & $\begin{array}{c}167 \\
(38.9 \%)\end{array}$ & $\begin{array}{c}36 \\
(8.4 \%)\end{array}$ & $\begin{array}{c}225 \\
(52.4 \%)\end{array}$ \\
\hline 11. It is common for ADHD children to have an inflated sense of self-esteem or grandiosity. & $\mathrm{F}$ & $\begin{array}{c}57 \\
(13.3 \%)\end{array}$ & $\begin{array}{c}84 \\
(19.6 \%)\end{array}$ & $\begin{array}{c}287 \\
(66.9 \%)\end{array}$ \\
\hline 14. ADHD children often have a history of stealing or destroying other people's things. & $\mathrm{F}$ & $\begin{array}{c}72 \\
(16.8 \%)\end{array}$ & $\begin{array}{c}42 \\
(9.8 \%)\end{array}$ & $\begin{array}{c}314 \\
(73.4 \%)\end{array}$ \\
\hline $\begin{array}{l}\text { 16. Current wisdom about ADHD suggests two clusters of symptoms: One of inattention and another } \\
\text { consisting of hyperactivity/impulsivity. }\end{array}$ & $\mathrm{T}$ & $\begin{array}{c}65 \\
(15.2 \%)\end{array}$ & $\begin{array}{c}27 \\
(6.3 \%)\end{array}$ & $\begin{array}{c}334 \\
(77.9 \%)\end{array}$ \\
\hline $\begin{array}{l}\text { 21. In order to be diagnosed as ADHD, a child must exhibit relevant symptoms in two or more settings } \\
\text { (e.g., home, school). }\end{array}$ & $\mathrm{T}$ & $\begin{array}{c}68 \\
(15.9 \%)\end{array}$ & $\begin{array}{c}45 \\
(10.5 \%)\end{array}$ & $\begin{array}{c}311 \\
(72.5 \%)\end{array}$ \\
\hline 26. ADHD children often have difficulties organizing tasks and activities. & $\mathrm{T}$ & $\begin{array}{c}111 \\
(25.9 \%)\end{array}$ & $\begin{array}{c}26 \\
(6.1 \%)\end{array}$ & $\begin{array}{c}289 \\
(67.4 \%)\end{array}$ \\
\hline
\end{tabular}

CA = Correct Answer; $\mathrm{T}=$ True $\mathrm{F}=$ False 
Table 4.

Participants' responses on the third subscale of KADDS which include 12 items pertain to the treatment of ADHD $(N=429)$.

\begin{tabular}{|c|c|c|c|c|}
\hline \multirow{2}{*}{ Items } & \multirow{2}{*}{ CA } & \multicolumn{3}{|c|}{ Number of responses } \\
\hline & & Correct & Incorrect & Don’t Know \\
\hline 2. Current research suggests that ADHD is largely the result of ineffective parenting skills. & $\mathrm{F}$ & $51(11.9 \%)$ & $66(15.4 \%)$ & $312(72.7 \%)$ \\
\hline 8. Antidepressant drugs have been effective in reducing symptoms for many ADHD children. & $\mathrm{T}$ & $\begin{array}{c}54 \\
(12.6 \%)\end{array}$ & $\begin{array}{c}56 \\
(15.2 \%)\end{array}$ & $\begin{array}{c}309 \\
(72.2 \%)\end{array}$ \\
\hline $\begin{array}{l}\text { 10. Parent and teacher training in managing an ADHD child are generally effective when } \\
\text { combined with medication treatment. }\end{array}$ & $\mathrm{T}$ & $\begin{array}{c}113 \\
(26.3 \%)\end{array}$ & $\begin{array}{c}37 \\
(8.6 \%)\end{array}$ & $\begin{array}{c}279 \\
(65.1 \%)\end{array}$ \\
\hline 12. When treatment of an ADHD child is terminated, it is rare for the child's symptoms to return. & $\mathrm{F}$ & $\begin{array}{c}58 \\
(13.5 \%)\end{array}$ & $\begin{array}{c}78 \\
(18.2 \%)\end{array}$ & $\begin{array}{c}292 \\
(68.1 \%)\end{array}$ \\
\hline $\begin{array}{l}\text { 15. Side effects of stimulant drugs used for treatment of ADHD may include mild insomnia and } \\
\text { appetite reduction. }\end{array}$ & $\mathrm{T}$ & $\begin{array}{c}69 \\
(16.1 \%)\end{array}$ & $\begin{array}{c}32 \\
(7.5 \%)\end{array}$ & $\begin{array}{c}328 \\
(76.5 \%)\end{array}$ \\
\hline 18. Individual psychotherapy is usually sufficient for the treatment of most ADHD children. & $\mathrm{F}$ & $\begin{array}{c}55 \\
(12.8 \%)\end{array}$ & $\begin{array}{c}60 \\
(14 \%)\end{array}$ & $\begin{array}{c}312 \\
(73.1 \%)\end{array}$ \\
\hline $\begin{array}{l}\text { 20. In severe cases of ADHD, medication is often used before other behavior modification } \\
\text { techniques are attempted. }\end{array}$ & $\mathrm{T}$ & $\begin{array}{c}64 \\
(14.9 \%)\end{array}$ & $\begin{array}{c}34 \\
(7.9 \%)\end{array}$ & $\begin{array}{c}330 \\
(76.9 \%)\end{array}$ \\
\hline $\begin{array}{l}\text { 23. Reducing dietary intake of sugar or food additives is generally effective in reducing the } \\
\text { symptoms of ADHD. }\end{array}$ & F & $\begin{array}{c}37 \\
(8.6 \%)\end{array}$ & $\begin{array}{c}115 \\
(26.8 \%)\end{array}$ & $\begin{array}{c}272 \\
(63.4 \%)\end{array}$ \\
\hline 25. Stimulant drugs are the most common type of drug used to treat children with ADHD. & $\mathrm{T}$ & $\begin{array}{c}34 \\
(7.9 \%)\end{array}$ & $\begin{array}{c}65 \\
(15.2 \%)\end{array}$ & $\begin{array}{c}327 \\
(76.2 \%)\end{array}$ \\
\hline $\begin{array}{l}\text { 34. Behavioral/Psychological interventions for children with ADHD focus primarily on the child's } \\
\text { problems with inattention. }\end{array}$ & $\mathrm{F}$ & $\begin{array}{c}36 \\
(8.4 \%)\end{array}$ & $\begin{array}{c}90 \\
(21 \%)\end{array}$ & $\begin{array}{c}303 \\
(70.6 \%)\end{array}$ \\
\hline $\begin{array}{l}\text { 35. Electroconvulsive Therapy (i.e. shock treatment) has been found to be an effective treatment } \\
\text { for severe cases of ADHD. }\end{array}$ & F & $\begin{array}{c}30 \\
(7 \%)\end{array}$ & $\begin{array}{c}19 \\
(4.4 \%)\end{array}$ & $\begin{array}{c}379 \\
(88.3 \%)\end{array}$ \\
\hline $\begin{array}{l}\text { 36. Treatments for ADHD which focus primarily on punishment have been found to be the most } \\
\text { effective in reducing the symptoms of ADHD. }\end{array}$ & $\mathrm{F}$ & $\begin{array}{c}78 \\
(18.2 \%)\end{array}$ & $\begin{array}{c}39 \\
(9.1 \%)\end{array}$ & $\begin{array}{c}311 \\
(72.5 \%)\end{array}$ \\
\hline
\end{tabular}

$\mathrm{CA}=$ Correct Answer; $\mathrm{T}=$ True; $\mathrm{F}=$ False .

\section{The KADDS subscales}

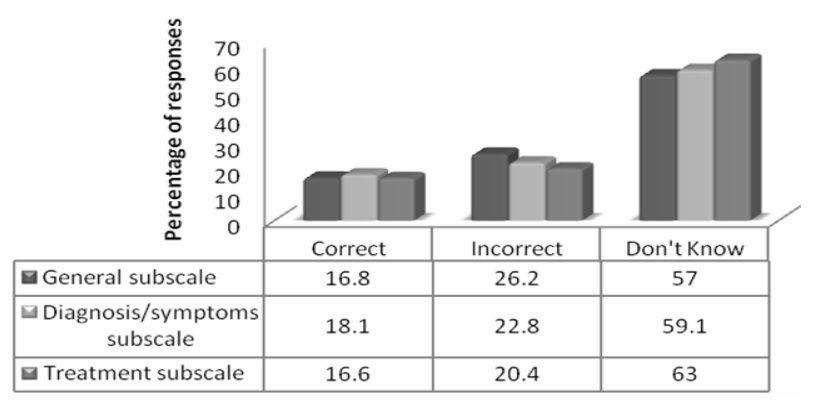

Figure 2.

Percentage of teachers' score of the correct, incorrect, and don't know responses on the KADDS subscales.

vestigate the relationship between teachers' level of knowledge of ADHD and their prior training and experience with ADHD (i.e., the number of ADHD courses taken in college or graduate level, and the number of workshops pertaining to ADHD ). The result of the correlational analysis was statistically significant $(\mathrm{r}$ $=0.311, p<0.01$ ). This result shows a strong positive correlation between teachers' level of knowledge of ADHD and their prior training and experience with ADHD.

Two-tailed Pearson correlation analysis was also carried out to examine the relationship between teachers' level of knowledge of ADHD and their level of confidence in teaching a student with ADHD. The result of the correlational analysis was statistically significant $(r=0.631, p<0.01)$. This result shows that teachers' level of knowledge of ADHD correlated posi- tively with their level of confidence in teaching a student with ADHD.

\section{Conclusion}

Teachers have a major role in the identification and assessment of students with ADHD. This study was intended to examine teachers' knowledge and misperceptions of ADHD. Three major study findings emerged. First, teachers' scores on KADDS were fairly low, pointing to a significant lack of knowledge about ADHD. Second, teachers' level of knowledge of ADHD was positively related to their prior training and experience with ADHD. Third, teachers' level of knowledge of ADHD correlated positively with their level of confidence in teaching a student with ADHD. Results from this study concur with the findings of previous studies (Bekle, 2004; Brooka et al., 2000; Canu \& Mancil, 2012; Ghanizadeh et al., 2006; Kos et al., 2004; Jerome et al., 1994; Ohan et al., 2008; Sciutto et al., 2000; Snider et al., 2003; Vereb \& DiPerna, 2004; West et al., 2005) showing that teachers lack adequate knowledge. Results from this study also bring light to the fact that teachers need to be educated and supported to further their professional development regarding ADHD through in-service training. Teachers who are knowledgeable about ADHD are better prepared to be in a position to offer adequate teaching, assistance, and support for children with ADHD (Goldstein et al., 2011; Lerner et al., 1995).

The limitations of this study that deserve consideration in future investigations include the instrumentation used to collect data. Sciutto and colleagues provide cited references for each item of KADDS. However, the existing research on ADHD is 
conflicting (Barkley, 2006; Cooper \& Ideus, 2002; Richard, 2000; Weiss \& Hechtman, 1993). Thus, using scientific literature to construct and support the KADDS is problematic. In addition, the KADDS, being a self-reported measure, is possibly subjective in nature. This research is also limited by the use of correlation analysis. This type of statistical analysis provides understanding the nature of relationships between variables, but it does not indicate what causes the relationship which limits drawing conclusions about outcomes and causes. Although the sample size was large $(n=429)$, there were a large number of unreturned questionnaires (78.55\%). The generalizability of the results is limited by low response rate $(21.45 \%)$ and the fact that only one geographical region was included in this study. In spite of these limitations, the results of this study are valuable for identifying areas where there is a misperception or lack of knowledge among teachers.

\section{Acknowledgements}

I would like to thank Professor Mark Sciutto who kindly gave his permission for the use of KADDS in this research. I also gratefully acknowledge that this research project was supported by a grant from the Research Center for the Humanities, Deanship of Scientific Research, King Saud University.

\section{REFERENCES}

AAP, American Academy of Pediatrics (2004). ADHD: A complete and authoritative guide. Elk Grove Village, I1: Author.

APA, American Psychiatric Association (2000). Diagnostic and statistical manual of mental disorders (4th ed.). Washington, DC: Author.

Barkley, R. (2006). Attention deficit hyperactivity disorder: A handbook for diagnosis and treatment. New York: Guilford Press.

Bekle, B. (2004). Knowledge and attitudes about Attention-Deficit Hyperactivity Disorder (ADHD): A comparison between practicing teachers and undergraduate education students. Journal of Attention Disorders, 7, 151-161.

http://dx.doi.org/10.1177/108705470400700303

Brooka, U., Watembergb, N., \& Gevac, D. (2000). Attitude and knowledge of attention deficit hyperactivity disorder and learning disability among high school teachers. Patient Education and Counseling, 40, 247-252.

http://dx.doi.org/10.1016/S0738-3991(99)00080-4

Bussing, R., Schoenberg, N., \& Perwien, A. (1998). Knowledge and information about ADHD: Evidence of cultural differences among African-American and white parents. Social Science \& Medicine, 46, 919-928. http://dx.doi.org/10.1016/S0277-9536(97)00219-0

Bussing, R., Gary, F., Leon, C, Garvan, C., \& Reid, R. (2002). General classroom teachers' information and perceptions of attention deficit hyperactivity disorder. Behavioral Disorder, 27, 327-339.

Canu, W., \& Mancil, E. (2012). An examination of teacher trainees' knowledge of attention-deficit/hyperactivity disorder. School Mental Health, 4, 105-114. http://dx.doi.org/10.1007/s12310-012-9071-3

Carey, W. (1999). Problems diagnosing attention and activity. Pediatrics, 103, 664-667. http://dx.doi.org/10.1542/peds.103.3.664

Curtis, D., Pisecco, S., Hamilton, J., \& Moore, D. (2006). Teachers perceptions of classroom intervention for children with ADHD: A cross-cultural comparison of teachers in the United States and New Zealand. School Psychology Quarterly, 21, 171-196.

http://dx.doi.org/10.1521/scpq.2006.21.2.171

Cooper, P., \& Ideus, K. (2002). Attention deficit/hyperactivity disorder: A practical guide for teachers. London: David Fulton Publishers Ltd.

Creswell, J. (2008). Educational research: Planning, conducting, \& evaluating quantitative and qualitative research. Upper Saddle River, NJ: Merrill Prentice Hall.

DuPaul, G., \& Stoner, G. (2003). ADHD in the schools assessment and intervention strategies. New York: The Guilford Press.
DuPaul, G., \& Weyandt, L. (2006). School-based intervention for children with attention deficit hyperactivity disorder: Effects on academic, social, \& behavioural functioning. International Journal of Disability, Development and Education, 53, 161-176. http://dx.doi.org/10.1080/10349120600716141

Barbaresi, W., \& Olsen, R. (1998). An ADHD educational intervention for elementary schoolteachers: A pilot study. Developmental and Behavioral Pediatrics, 19, 94-100. http://dx.doi.org/10.1097/00004703-199804000-00006

Gall, M., Gall, J., \& Borg, R. (2007). Educational research: An introduction (8th ed.). New York, NY: Pearson Education.

Ghanizadeh, A., Bahredar, M., \& Moeini, S. (2006). Knowledge and attitudes towards attention deficit hyperactivity disorder among elementary school teachers. Patient Education and Counselling, 63, 84-88. http://dx.doi.org/10.1016/j.pec.2005.09.002

Goldstein, S., Naglieri, J., \& DeVries, M. (2011). Learning and Attention Disorders in Adolescence and Adulthood: Assessment and Treatment (2nd ed.). John Wiley \& Sons. http://dx.doi.org/10.1002/9781118093085

Herbert, J., Crittenden, K., \& Dalrymple, K. (2004). Knowledge of Social Anxiety Disorder Relative to Attention Deficit Hyperactivity Disorder Among Educational Professionals. Journal of Clinical Child and Adolescent Psychology, 33, 366-372. http://dx.doi.org/10.1207/s15374424jccp3302_18

Jerome, L., Gordon, M., \& Hustler, P. (1994). A comparison of American and Canadian teachers' knowledge and attitudes towards Attention Deficit Hyperactivity Disorder (ADHD). Canadian Journal of Psychiatry, 39, 563-567.

Lerner, J., Lowenstein, B., \& Lerner, S. (1995). Attention deficit disorders: Assessment and teaching. Pacific Grove, CA: Brooks/Cole.

Kos, J., Richdale, A., \& Jackson, S. (2004). Knowledge about attention deficit hyperactivity disorder: A comparison of in-service and preservice teachers. Psychology in the Schools, 41, 517-526. http://dx.doi.org/10.1002/pits.10178

Ohan, J., Cormier, N., Hepp, S., Visser, T., \& Strain, M. (2008). Does knowledge about attention-deficit/hyperactivity disorder impact teachers' reported behaviors and perceptions? School Psychology Quarterly, 23, 436-449. http://dx.doi.org/10.1037/1045-3830.23.3.436

Pelham J., \& Evans, W. (1992). Teacher ratings of DSM-III-R symptoms for the disruptive behavior disorders: Prevalence, factor analysis, \& conditional probabilities in a special education sample. School Psychology Review, 21, 285-300.

Richard, M. (2000). Dispelling the myths and misconceptions about ADHD. In: B. Guyer (Ed.), ADHD: Achieving success in school and life. Boston: Allyn and Bacon.

Soroa, M., Gorostiaga, A., \& Balluerka, N. (2013). Review of Tools Used for Assessing Teachers' Level of Knowledge with Regards Attention Deficit Hyperactivity Disorder (ADHD). In S. Banerjee (Ed.), Attention Deficit Hyperactivity Disorder in Children and Adolescents. http://dx.doi.org/10.5772/50252

Sciutto, M., Terjesen, M., \& Bender, A. (2000). Teachers' knowledge and misperceptions of Attention-Deficit/Hyperactivity Disorder. Psychology in the Schools, 37, 115-122. http://dx.doi.org/10.1002/(SICI)1520-6807(200003)37:2<115::AIDPITS3>3.0.CO;2-5

Sciutto, M. J., \& Eisenberg, M. (2007). Evaluating the evidence for and against the overdiagnosis of ADHD. Journal of Attention Disorders, 1, 106-113. http://dx.doi.org/10.1177/1087054707300094

Selikowitz, M., (2004). ADHD: The facts. Oxford: Oxford University Press.

Snider, V., Busch, T., \& Arrowood, L. (2003). Teacher knowledge of stimulant medication and ADHD. Remedial and Special Education, 24, 46-56.

Vereb, R., \& DiPerna, J. (2004). Teachers' knowledge of ADHD, treatments for ADHD, \& treatment acceptability: An initial investigation. School Psychology Review, 33, 421-428. http://dx.doi.org/10.1177/074193250302400105

West, J., Taylor, M., Houghton, S., \& Hudyma, S. (2005). A comparison of teachers' and parents' knowledge and beliefs about attentiondeficit/hyperactivity disorder (ADHD). School Psychology International, 26, 192-208. http://dx.doi.org/10.1177/0143034305052913 


\section{K. D. F. ALKAHTANI}

White, S., Sukhodolsky, D., Rains, A., Foster, D., McGuire, J., \& Scahill, L. (2011). Elementary school teachers' knowledge of tourette syndrome, obsessive-compulsive disorder, \& attention-deficit/hyperactivity disorder: Effects of teacher training. Journal of Developmental and Physical Disabilities, 23, 5-14.

http://dx.doi.org/10.1007/s10882-010-9209-x
Weiss, G., \& Hechtman, L. (1993). Hyperactive children grown up. New York: Guilford Press.

Weyandt, L., Fulton, M., Schepman, S., Verdi, G., \& Wilson, K. (2009). Assessment of teacher and school psychologist knowledge of attention-deficit/hyperactivity disorder. Psychology in the Schools, 46, 951-960. http://dx.doi.org/10.1002/pits.20436 